\title{
Tertiary Cataract- A Rare Postoperative Complication after Cataract Surgery: A Case Study
}

\author{
Seema Channabasappa ${ }^{1}$, Sheetal Girimallanavar ${ }^{2}$, Aiswarya Ann Jose ${ }^{3}$, \\ Divya Rose Cyriac ${ }^{4}$
}

\author{
${ }^{1}$ Professor, Ophthalmology, MS, VIMS \& RC, Bengaluru, Karnataka, India \\ ${ }^{2}$ Assistant Professor, Ophthalmology, MS, DNB, VIMS \& RC, Bengaluru, Karnataka, India \\ ${ }^{3}$ Junior Resident, Ophthalmology, VIMS \& RC, Bengaluru, Karnataka, India \\ ${ }^{4}$ Junior Resident, Ophthalmology, VIMS \& RC, Bengaluru, Karnataka, India
}

Corresponding Author: Sheetal. V. Girimallanavar

\begin{abstract}
Introduction: IOL opacification is a rare and serious complication of post operative diminution of vision with the only effective treatment being lens explantation and replacement, preferably involving lens of different material ${ }^{1}$. Following cataract surgery, it can occur anytime varying from months to years after the surgery.

Case Report: A 57-years-old male presented with chief complaints of left eye diminution of vision since 2 years which was painless and progressive. Patient had undergone both eyes cataract surgery 4 years back elsewhere. He was a known case of Ischemic Heart Disease on treatment. On examination, his best corrected visual acuity (BCVA) was 6/9 in right eye and 6/36 in left eye. On slit light examination, there was presence of white pupillary reflex in left eye giving appearance of white cataract. On dilated examination, both eyes were found to be pseudophakic with left eye having posterior chamber opacified foldable Intra Ocular Lens and posterior segment details in left eye were not visible. B Scan was done and noted to be normal.He was posted for Left eye IOL (Intra Ocular Lens) exchange with rigid IOL Implantation with surgical capsulotomy after which his vision improved.
\end{abstract}

Conclusion: Cases of opacified Intraocular lenses if visually significant require IOL exchange procedure for treatment which is associated with good visual prognosis.

Keywords: Pseudophakia, Intra Ocular Lens (IOL), Opacified IOL, Acrylic, Hydrophilic, Hydrophobic

\section{INTRODUCTION}

IOL opacification is a rare and serious complication of post operative diminution of vision with the only effective treatment being lens explantation and replacement, preferably involving lens of different material ${ }^{1}$ Following cataract surgery, it can occur anytime varying from months to years after the surgery. Opacification is most common with hydrophilic acrylic lens, and is less common with hydrophobic acrylic lenses or silicon lenses. Lens clouding shows greater incidence in diabetics and those patients should be subjected to more frequent and prolonged follow up. It mainly occurs due to deposition of calcium salts on the surface of lens which increase over time.

\section{CASE REPORT}

A 57 year old male presented to the outpatient department with complaints of decreased vision in left eye since 2 years. It was painless and progressive. He had undergone both eye cataract surgeries 4 years back. He was a known case of Ischemic Heart Disease on treatment. He had no other comorbidities. Family history 
Seema Channabasappa et.al. Tertiary cataract- a rare postoperative complication after cataract surgery: a case study.

was insignificant. On examination his Best Corrected Visual Acuity (BCVA) was 6/9 in RE (Right Eye) and 6/36 in LE (Left Eye). On slit lamp examination there was a white reflex in left eye mimicking a cataract and shimmering light reflexes of the intraocular lens were noted in RE. Detailed dilated examination with slit lamp revealed opacification of both optic and haptic of the intra ocular lens in LE with posterior segment details in Left Eye not visible. B Scan was done and noted to be normal in both eyes. The patient was diagnosed with both eyes pseudophakia and LE intraocular lens opacification. He was educated about his findings, prognosis and treatment protocol. He was posted for Left eye IOL Exchange with rigid IOL Implantation with SOS surgical capsulotomy. A scan biometry was done and IOL power for Left eye was +22.00 D. Patient underwent an uneventful IOL exchange procedure in LE with acrylic hydrophobic IOL. The pre operative and post operative period after the first surgery was described to be uneventful by the patient and the condition of patient during follow up period is presented in Table1.

Table1:

\begin{tabular}{|l|l|l|l|}
\hline LEFT EYE & AT PRESENTATION & POST OP DAY 1 & FOLLOW UP AFTER 2 WEEKS \\
\hline BCVA & $6 / 36$ & $6 / 9$ & $6 / 6($ P) \\
\hline $\begin{array}{l}\text { ANTERIOR } \\
\text { SEGMENT }\end{array}$ & & & \\
\hline WOUND & & HEALTHY & HEALTHY \\
\hline SECTION & NORMAL & OPPOSED & NORMAL \\
\hline LIDS & NORMAL & NORMAL & NORMAL \\
\hline CONJUCTIVA & CLEAR & MILD CONGESTION + & CLEAR \\
\hline CORNEA & QUIET & CLEAR & QUIET \\
\hline $\begin{array}{l}\text { ANTERIOR } \\
\text { CHAMBER }\end{array}$ & NORMAL CELLS & NORMAL \\
\hline IRIS & ROUND,REGULAR,REACTIVE & $\begin{array}{l}\text { PHARMACOLOGICALLY } \\
\text { DILATED }\end{array}$ & ROUND,REGULAR,REACTIVE \\
\hline PUPIL & & PCIOL+ & PCIOL+ \\
\hline LENS & OPACIFIED PCIOL +,PCO & $\begin{array}{l}\text { DISC AND } \\
\text { NORMAL }\end{array}$ & DISC AND MACULA NORMAL \\
\hline FUNDUS & NO VIEW & \\
\hline
\end{tabular}

Image of the opacified IOL is as shown in Figure $1 \& 2$

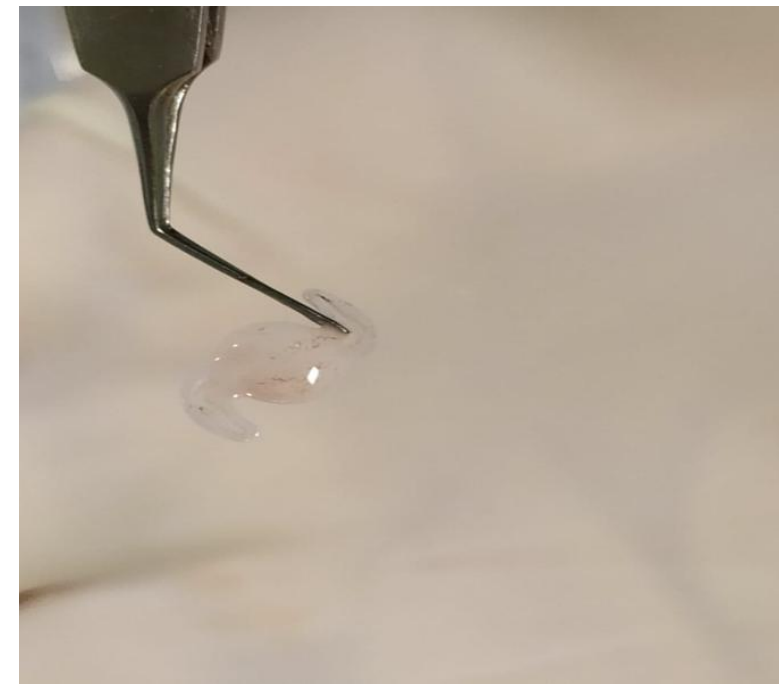

Figure1

\section{DISCUSSION}

The number of IOL implantations is growing daily worldwide, but fortunately, complications related to foldable acrylic

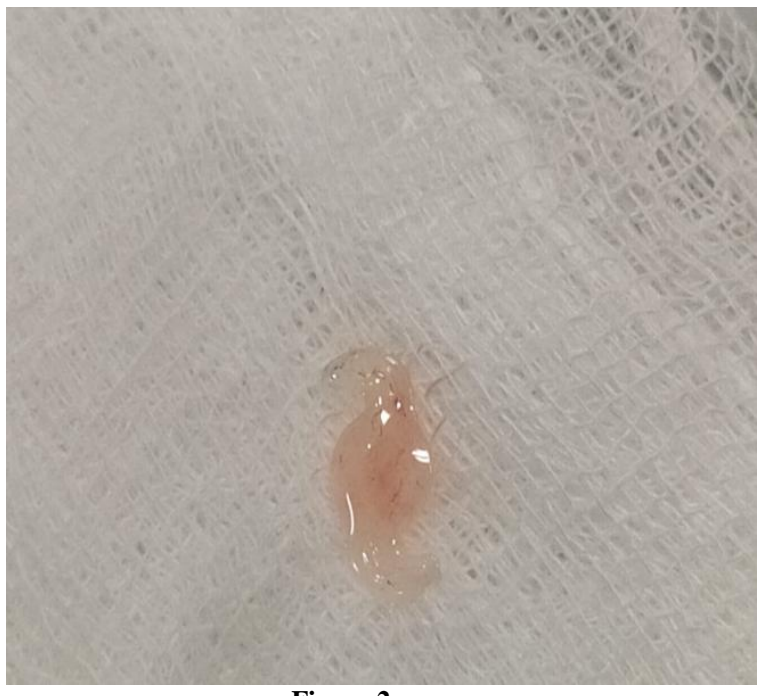

Figure 2

IOL itself are rare. The IOL opacification is a rare complication, usually occurring in the late postoperative period in hydrophilic Intra Ocular Lenses. ${ }^{2}$ The exact causes and 
Seema Channabasappa et.al. Tertiary cataract- a rare postoperative complication after cataract surgery: a case study.

patho-mechanisms for opacification still remain unknown. ${ }^{3}$ One major cause of IOL opacification can be calcification ${ }^{4}$. Calcium content of normal aqueous humour is low and is half of the serum level. The formation of calcium deposits may be attributed to the fact that aqueous humour is supersaturated with crystalline calcium. Calcification may be on the outer surface or in the inner part of the IOL. ${ }^{5}$ Calcification occurs on foreign surfaces such as implants as well as vessel walls after a long contact with supersaturated biological fluids.

Disturbance of the blood-aqueousbarrier due to some underlying conditions is also thought of being a contributory factor to the process of opacification. ${ }^{6}$ Systemic diseases such as diabetes were also implied in the pathogenesis of IOL calcification but whether changes in blood aqueous barrier is responsible here for the opacification is not clear. $^{7,8}$

This condition of IOL opacification, can usually be confused with white cataract (mature or hypermature) or secondary cataract (posterior capsular opacification), hence the term, "Tertiary cataract.,"

Thus a careful preoperative evaluation including careful slit lamp examination and dilated examination is very important in diagnosing this condition to prevent intraoperative surprises. ${ }^{2}$

Careful removal of implanted IOL from pre-existing capsulorrhexis is a critical step during surgery and minimum traction on the capsule would reduce the risk of zonular dehiscence or posterior capsule rupture. ${ }^{9}$ Complications involved in such surgeries include zonular dehiscence, rupture of the posterior capsule and corneal decompensation.

\section{CONCLUSION}

These cases of opacified Intraocular lenses if visually significant require IOL exchange procedure for treatment which is associated with good visual prognosis

Acknowledgement: None

\section{Conflict of Interest: None}

\section{Source of Funding: None}

\section{REFERENCES}

1. Neuhann IM, Neuhann TF, Szurman P, Koerner S, Rohrbach JM,Bartz-Schmidt KU. Clinicopathological correlation of 3 patterns of calcification in hydrophilic acrylic intraocular lens. J Cataract Refract Surg 2009; 35:593-7.

2. Gupta G, Goyal P, Bal A, Jain A, Malhotra C. Pearly white intraocular lens opacification - "Tertiary cataract", Indian Journal of Ophthalmology January 2020; Vol 68,Issue1:188-189.

3. Izak AM, Werner L, Pandey SK, Apple DJ. Calcification of modern foldable hydrogel intraocular lens designs Eye (Lond). 2003;17:393-406

4. Gartaganis SP, Kanellopoulou DG, Mela EK, Panteli VS,Koutsoukos PG. Opacification of hydrophilic acrylic intraocular lens attributable to calcification: investigation on mechanism Am J Ophthalmol 2008; 146:395-403.

5. Choi SM, Yang WK, Yoo YW, Lee WK. Effect of surface modification on the in vitro calcium phosphate growth on the surface of poly (methyl methacrylate) and bioactivity. Colloids Surf B Biointerfaces 2010; 76:326-33.

6. Morgan-Warren PJ, Andreatta W, Patel AK. Opacification of hydrophilic intraocular lenses after Descemet stripping automated endothelial keratoplasty. Clin Ophthalmol 2015;9: 277-83.

7. Yu AK, Kwan KY, Chan DH, Fong DY. Clinical features of 46 eyes with calcified hydrogel intraocular lenses. J Cataract Refract Surg 2001; 27:1596606.

8. Kim CJ, Choi SK. Analysis of aqueous humor calcium and phosphate from cataract eyes with and without diabetes mellitus. Korean J Ophthalmol 2007; 21:90-4. 
Seema Channabasappa et.al. Tertiary cataract- a rare postoperative complication after cataract surgery: a case study.

9. Jarwal PN, Singh R, Vseem K, How to cite this article: Channabasappa S, Choudhary N. Total Opacification of Girimallanavar S, Jose AA et.al. Tertiary Intraocular Lens Implant After Uncomplicated Cataract Surgery: A Case Report Delhi J Ophthalmol 2019; 29;64-66 cataract- a rare postoperative complication after cataract surgery: a case study. Int $J$ Health Sci Res. 2021; 11(9):133-136. DOI: https://doi.org/10.52403/ijhsr.20210920 